\title{
Tadashi Takenouchi
}

\section{Capurro's Hermeneutic Approach to I nformation Ethics: Ethos in the Information Society and the Development of "angeletics"}

\begin{abstract}
:
Rafael Capurro is one of the pioneers of the hermeneutic approach to information studies, especially with regard to ethical issues. One of the main goals of his study is to understand "ethos" in the information society. Capurro's ideas concerning the information technology are different from those of Dreyfus although they both have hermeneutic viewpoints. The scope of his study is widened in his latest study named "angeletics" which means "message studies." Angeletics, hermeneutics, and mediology are complementary to each other. Capurro's idea concerning ethics in the information age is based on "technologies of the self" which are not "act-oriented" but "self-oriented." It is also expected that interactions between Capurro and Japanese thought patterns produce some important contributions to information ethics.
\end{abstract}

\section{Agenda}

Ethos in the Information Society

Capurro's hermeneutic approach

Pre-understanding (Vorverständnis)

Project (Entwurf)

Information Gestell (Informations-Gestell)

Development of "Angeletics"

Ethics in the Information Age

Cooperation toward others

Open relativism

Plural perspective

Ecological thinking

Capurro and Japanese Perspective

\section{Author:}

Tadashi Takenouchi:

- Assistant Professor, Interfaculty Initiative in Information Studies, University of Tokyo, 7-3-1 Hongo, Bunkyo-ku, Tokyo, 113-0033, Japan

- 熏 +81 - 3 - 5841 2385, $ه$ take@iii.u-tokyo.ac.jp, 吕 http://homepage2.nifty.com/tempural

- Relevant publications:

- This is a modified and enlarged version of a paper (in Japanese) presented at: Shiso (Thought), Tokyo: I wanami shoten, 7, No. 951 (2003). pp.69-88 


\section{Ethos in the Information Society}

Studies on information phenomena from the viewpoint of hermeneutics, which was developed by Martin Heidegger and Hans-Georg Gadamer, can be called "hermeneutic information studies" or "hermeneutic informatics." Rafael Capurro (1945- ), philosopher and information scientist, is one of the pioneers of this field. The issues he addresses are quite various: Studies concerning Heidegger, the genealogy of information, hermeneutics of information retrieval, ethics in the information age, media ethics, and digital ontology. Especially his hermeneutic approach to information ethics is an important contribution to this field.

As is generally known, information ethics is a kind of applied ethics such as bioethics and environmental ethics. It is a relatively new discipline which addresses the problems brought by rapidly pervading technology and computer networks. It focuses on common problems such as privacy protection, regulation of potentially injurious contents, responsibility for administrators of the networks or engineers, release of communication records to the police, and copyright protection. Media ethics, which had been discussed before the Internet became popular, is now a part of information ethics.

Studies on information ethics today often deal with these problems through the following approaches: How to teach morals to individuals through "formal education" processes such as schools, how to establish ethical professional codes, or how to develop regulations or laws. These are efforts to maintain ways of regulating society through legislation. It is often the case with this way of thinking to separate information and its technology from existential viewpoints based on the practice of living.

Given the background of this separation, there is the assumption of neutrality with regard to information technology. Capurro throws such ideas into doubt and deeply redefines the relationship between information technology and existential practices of living. Technologies are by no means neutral, and it is also true of information technology. There is no independent substance such as "information itself" similar to Kant's concept of the "thing itself". Information is deeply affected by subjectivity or existential activities. Capurro insists that information technology in itself takes on ethical characteristics, drawing information and its technology back to the field of our daily lives and casting it in multi-layered or multi-dimensional contexts.
Then Capurro turns his analysis to "ethos in the information society." Although his concept of "ethos" is difficult to define clearly, it can be regarded as a practical attitude which provides the context where information technology is located in certain circumstances. It is this problem of "ethos" that Capurro emphasizes using expressions such as "being intertwined" or impartibility between technologies and ethics. To investigate ethos in the information society means to deal with the dimension where information technology and our existential lives are intertwined. As a tool that can be used in order to grasp this dimension, the viewpoint of "hermeneutics" definitely plays an important role. Thus, the concept of "hermeneutic turn" is proposed as the paradigm shift to the new informatics to investigate ethos in the information society. This is the most important framework of Capurro's argument.

\section{Capurro's hermeneutic approach}

Capurro's hermeneutic turn consists of three key concepts:

\section{Pre-understanding (Vorverständnis)}

This is originally a technical term from Gadamer's philosophical hermeneutics. Capurro uses this concept in order to overcome disunion between information technology and the practice of our living. For example, even a programming language, which seems to have no intersection with our lives, makes sense only when it is used by those who have preunderstanding or pre-existing purposes to use it. In that sense, it reflects the horizons of meanings. Every text as well as daily tools are intertwined in the meaning of our living, expecting preunderstandings in reading or in use. Information and its technologies are also inseparably related to pre-understandings of developers, managers, users, or governors as their framework.

\section{Project (Entwurf)}

Entwurf (project or casting) is a key concept of Heideggerian philosophy which represents the way of being of Dasein (there-being), that is, being cast in history and casting or projecting self for the future at the same time. Entwurf has a number of meanings such as project, casting, designing, or planning. Using this concept as a metaphor, Capurro emphasizes that projecting or casting our "selves" are inseparable, and concerning not only computer programming, but also the development of the 
whole world of information. The relationship between the practice of living and information (technology) creates ethos in the information society. Projecting "self" is at the same time projecting one's relationship with others, and, in that sense, projecting to the world. This projection provides the background of the next understanding. Therefore, this concept is an indispensable factor of hermeneutic circulation and is strongly connected to the "preunderstanding" that is already shown.

\section{Information Gestell (Informations-Gestell)}

"Gestell" is also a technical term of Heideggerian philosophy (especially concerning technologies) which represents modern technologies as an autonomous system having an axis of usefulness that affects human beings. Capurro thinks that information technology also has this structure of "Gestell." When we see information technology, in the Heideggerian meaning, not as things (Vorhandensein) but as tools (Zuhandensein), and information and its technology are seen in the context of our lives, then we can also see the opposite situation where we are driven by them.

We can see that Capurro has tried to apply these hermeneutic ideas to information studies since his early study concerning the "hermeneutics of information retrieval." (Capurro 1986) In this study, his hermeneutic model of information retrieval is shown in contrast with traditional models of "rational" information behavior. According to Capurro, information retrieval is not a "right" access to the "rationally" organized system of information as "objective" knowledge. Information systems themselves reflect pre-understandings of developers or situations surrounding them, and users or searchers get information or meanings casting their preunderstandings into systems. We can see these movements as hermeneutic processes. Although classifications in libraries or thesauri in databases may look like closed systems, actually they reflect pre-understandings or horizons of meanings based on various activities in the outer world and have various characteristics in different times and spaces. This hermeneutic analysis on information retrieval is the starting point of Capurro's hermeneutic approach to information studies.

After that, the scope of his study went beyond the framework of information retrieval. From a hermeneutic viewpoint, he addresses the overall relationship between information and human lives, an informatic view of human beings, current issues concerning the information society, and information ethics in a wider meaning. It is in these studies where "ethos" or the intertwining of information technology and practices of our lives, as I mentioned above, is discussed as an important problem, and the hermeneutic turn of informatics becomes clear. It is not likely that computer hardware, software, or any kind of information media and its contents are created by those who are "independent" from their own lives in society or communities. In fact, the meanings or ways of being of information and its technology in society or communities are determined ontologically based on horizons consisting of their pre-understandings. Furthermore, these pre-understandings are by no means personal, but co-operational behaviors with others in "a" shared world. Therefore, they have ethical problems at the same time.

To view information and its technology from the perspectives of the relationships in our lives, Capurro returns to Aristotelian thought (according to Heidegger). Capurro follows Aristotelian characterization between techne (technical knowledge) concerning poiesis (production) and phronesis (practical knowledge) concerning praxis (practice). The former is based on the latter. Techne is partial knowledge concerning fragmentary technical acts of poiesis, while phronesis means knowledge concerning practical relationships. Poiesis or techne have specific meanings only when they are related to praxis. This praxis is exactly what Capurro thinks as the holistic image of our lives. He associates phronesis with the concept of "foreseeing (Vor-Sicht)" which Heidegger pointed out as one of the factors of the "prestructure of understanding" (Vor-Struktur des Verstehens). Capurro regards phronesis as the central virtue in technical acts. It is an ability to see through the relationships of meanings, that is, the inseparable, interactive, and tight relationships between information technology and human lives, the "outer" and "inner" world, theories and practices, science and technology, and self and others. Whether we are aware of it or not, we always have some kind of outlook on certain plural relationships of meanings in our holistic human lives. Through practice, foresight is put into hermeneutic circulation, which leads to a new understanding or way of seeing. In this process, fixed statements or casuistic norms which provide problems and solutions in advance have slight significance but do not have ultimate authority. The plasticity or flexibility of human lives, in other words, the possibility of projection, provides the key to understanding Capurro's hermeneutic approach. It is certain that "ethos" is formed by humane interaction of meanings, involvement, and discretion through interpretation and response. 
This interpretation is also similar to that of Hubert $L$. Dreyfus, who discusses information technology from a Heideggerian viewpoint and who mentions the Aristotelian concept of phronesis. In some regards Dreyfus and Capurro have very similar positions, but they are different from each other in subtle but important perspectives. One reason for the difference is that Dreyfus developed his study concerning issues on the nature of being of artificial intelligence or robotics while Capurro first started his study on information retrieval, that is, human behavior itself. Dreyfus emphasizes the nature of information as tools based on the first half of Heidegger's "Time and Being". Capurro also discusses that point, but he emphasizes the hermeneutic structure of preunderstandings, mentioning the fact that information and its technology are essential components for us to form our lives.

In addition, Dreyfus concludes that it is impossible for us to make self realizations in cyberspace, for the totality of relationships in our lives is lost there because of the lack of corporeality. Whereas Drefus set information technology against the life-world and supposes a "pure" humane or fundamental world which has not been invaded by information media, Capurro thinks that information technology is "already embedded" in our life-world. In other words, Capurro thinks the life-world is the world which is variously characterized by information technology and media. The life-world seen as such can and should be always newly designed by both personal existential and information technological designing.

\section{Development of "Angeletics"}

Capurro has developed his hermeneutic approach and presented a new theoretical framework called "angeletics." As the concept of "information" is quite ambiguous, he has turned his eyes to the concept of "message" in order to concentrate on the aspect of "transmission of meaning" and has tried to describe the structures and developments of various message phenomena in history. He named this particular study concerning message phenomena "angeletics" or "Angeletik", derived from the Greek word angelía which means message.

In developing angeletics, Capurro tries to complement the hermeneutic approach. Hermeneutics theorizes pre-understandings or horizons of meanings and analyzes them. However, it does not deal with how they were originally generated or formed. Moreover, hermeneutics addresses interpretation of "something transmitted," but does not address "transmitting." Angeletics is considered to be a comprehensive framework in which the mechanisms of generation, formation, sharing, or transmitting of these pre-understandings or horizons of meanings are discussed.

To describe generation or transmission of messages in history, it is necessary to see how the horizons of meanings or pre-understandings have been formed from a historical viewpoint.

Capurro says that message transmission has two types of structure referred to as "dialogical" and "discursive" in the communicology of Flusser. The former is a structure where new messages are produced, and the latter is one that becomes clear when (new) messages are spread. Capurro regards the former structure as "horizontal = interactive" and the latter as "vertical = one way." The expression of "vertical" implies the image that messages are transmitted from top to bottom with authority or power. Capurro points out the dialectic relationship woven by these horizontal and vertical structures in (western) history. He takes up three eras as model cases.

The first case is ancient Greece. In the pre-Socrates era, the vertical structure of message transmission, by which gods make their intents known to humans, was dominant. The messengers who delivered the gods' messages to humans were poets or oracles. Such structure of messages was determined by religious and political authorities and constituted the core of society. In addition to this vertical structure of messages, a horizontal one was developed through the dialogical culture of sophists and the philosophies of Socrates and Plato. As such, the vertical structure of messages took the place of the horizontal one. But this does not mean that the vertical one disappeared completely.

The second case is the Age of Enlightenment. For a long time after the collapse of the Roman Empire, Christianity was located in the core of western message culture, that is, the dominant vertical message structure based on the connection between religion and political power. In the Age of Enlightenment, the dialectical relationship between vertical and horizontal structures appears again, being different from that of ancient Greece. Capurro thinks that the vertical structure of messages in this era was based on orders or norms characterized by churches and civil society. Those were given conditions. On the other hand, he thinks that communications among researchers through publications allowed the horizontal message structure to gain 
power. This view of publishing technology as an apparatus to enable the horizontal interaction of messages and to assure the freedom of thought beyond the level of earthly human relationships is along the lines of Kant's views as shown in "An Answer to the Question: What is Enlightenment?" or "What Does It Mean to Orient Oneself in Thought?"

The third case is in the age of electronic media, that is, the modern times. Mass media, which Harbermas criticizes as possessing a one-way character, is regarded as the basis of the vertical message structure. The Internet, on the other hand, is regarded as a new infrastructure which enables us to communicate horizontally. The Internet provides all kinds of message transmission: One to one, one to many, many to one and many to many. This is a rather unique situation in history; therefore it is worth analyzing from the viewpoint of the "message society." This horizontal message structure in the Internet Age is one of the main targets of angeletics. Even if the Internet weakens the dominance of the vertical structure of mass media to some extent, it will continue to have crucial influence on our daily lives. This struggle for power is also the theme of angeletics.

When it comes to historical approaches to "transmission" phenomena, Régis Debray's work on mediology may be a useful starting point. Debray developed his mediology by adapting Marxism to "media" studies but in a wider context. He analyzes the mechanisms of the organization of authority structures in transmission phenomena, using the contributing factors of realization or extension of influences of political movements (French Revolution and socialism) or religious doctrines (Trinitarianism of Christianity) as model cases. In mediology, however, "communication" as a horizontal process is not regarded as important for the self realization of such thoughts or movement, and "transmission" is at all points determined by authorities or powers; that is, regarded as top-down construction (in Capurro's words, "vertical" construction). Debray emphasizes that organizing material factors brings about the development of specific thoughts: In the case of Christianity, for example, "church buildings" functioned as a means of accepting the words of God and "Communion bread" made them accept the Incarnation.

Debray tends to regard material things as apparatus of transmission, but ignores emergent factors in each transmission. Although the roles of material things in the transmission of meanings are important, it is not true that transmission is determined only by factors in the "outer" world such as material apparatus or social organizations. It is better to think that such factors influence some kinds of meaning transmission only when they are located in specific contexts of "inner" worlds or given meanings shared in communities or society. Even if there were the same material apparatus, there must be other possibilities of meaning transmission according to "ethos" or pre-understandings. This is one of the most important differences between angeletics and mediology: The former considers message phenomena not only on the level of material or "outer" factors, but also of subjective or "inner" factors. In other words, it is one of the main tasks of angeletics to investigate how horizons of meanings ("ethos" or shared pre-understandings) themselves are formed and how such subjective factors give meaning to material factors in message or meaning transmission. To put it more directly, mediological studies can be seen as a part of angeletics in a sense because all kinds of messages, senders, mediators, and receivers are in the scope of angeletics while only "media" are regarded as producers of transmission in mediology. In other words, angeletics is an idea that comprehends mediological viewpoints. Hermeneutics, angeletics, and mediology are complementary to one another in studies on human interaction. Both angeletics and mediology treat the aspect of "transmission" from a wide perspective that is not covered by hermeneutics. Mediology concentrates on "outer" factors such as social organization or material media rather than the generation of meaning or ideology. Angeletics emphasizes "inner" factors such as pre-understandings or horizons of meanings, which are common to hermeneutics, and investigates various aspects of "ethos" by considering the roles or relationships of senders, mediators, and receivers. Capurro tries to theorize angeletics based on Heidegger's "pre-structure of understanding." This means that message is considered to have ontological character and therefore a relationship with the world of human existence.

Capurro thinks that "angeletic turn" comes after "hermeneutic turn." This is a trial to extend the range of the hermeneutic approach in informatics to generation and the transmission of meanings taking over its fruitful outcome. The construction of angeletics has just started, and Capurro expects our coming contributions to develop this field of study.

\section{Ethics in the Information Age}

What does Capurro think ethics in the information age should be? He discusses this question by refer- 
ring to Foucault's idea of "technologies of the self." Foucault distinguishes among four types of technologies: of producing, of symbolization, of governing and of the self. Whereas the former three are related to "act-oriented" ethics or "norms," only the last one is related to "self-oriented" ethics or "forms" of our lives in which we exactly face our own "selves". As I mentioned at the beginning of this article, mainstream studies on information ethics so far have dwelt on problems such as morals, regulations, norms or standards. These are apparently "act-oriented" ethics, and Capurro thinks that they do not make up a sufficient condition for us to live well in the information age. Since information and information technology is directly related to the formation of our lives, it is quite important for us to reflect upon self-oriented ethics, to think from "inside" ourselves with regard to matters of information ethics, rather than establish norms from "outside."

In this case, however, the "self" does not mean "ego." Whereas "ego" is a capsule-like, isolated consciousness which does not include others, the "self" is "I as we and we as I", which makes a relationship with others sharing a common environment. Construction of living with others like this is what Capurro calls "self-formation (Selbstformung)," and ethics on that level is undoubtedly self oriented.

The self-oriented ethics that Capurro proposes has four characteristics as follows:

\section{Cooperation toward others}

The concept of "technologies of the self" as interpreted by Capurro is a slightly different from that of Foucault. While Foucault treats the formation of ethical selves as self oppression toward specific models in history, Capurro emphasizes positive selfprojection (Selbstformung) to create relationships with others, especially those from whom we are alienated or those whom we can recognize only through information media. "We are exposed to the place where we can form - and sometimes destroy - our lives not only with others but also for others."(Capurro 1995: 44) As I already mentioned, Capurro doesn't think that "ethical problems can be solved by codes or prescriptions, at least when they are not understood as beginnings of the discussion. Reflections on ethics themselves can and should produce a new "ethos" in the mid and long term."(Capurro 1999)

\section{Open relativism}

Capurro has doubts about attempts to develop "universal" information ethics codes by the United Nations or such organizations. Although the Internet has brought us universal access that overreaches borders, every country has relatively different cultural bases, so a single code or set of norms concerning information ethics will not be accepted by all of them. In Germany, for example, it is forbidden to make public information to support Nazism, but it is not possible to control the information found on websites of other countries. It is the same in the case of the influx of pornography to Islamic countries. In some countries it is restricted or forbidden to use the Internet. These problems cannot be solved at once by developing a "universal" code. Concerning information ethics it seems impossible to find a dogmatic criterion or a universal system. Rather it is important for us to create ways to use information and its technology to maintain relativity, following each culture or way of living. At the same time, however, we should avoid allowing relativism to become dogmatic, exclusive, or uncommunicative. Relativity with room for having dialogues with other systems is desirable.

\section{Plural perspective}

To see plural relationships means to reject reductionism, that is, to reduce everything to a single relationship. Human beings are reduced - or even taken apart - in the process of oxidization by biologism, to the system of stimulus-response by psychologism or to social elements by sociologism. Likewise informatism reduces or takes apart everything (of course including human beings) to a single relation where even our spirits or ethos are regarded as mere information processing. Informatism leads to information technology-centered ideas where humans are driven to acquire more and more information (mainly computer) skills to be excellent homo informaticus, while those who have poor information skills are looked down upon. These reductionisms ultimately eliminate and ignore our life-world consisting of humane meanings." The hermeneutic approach including participation by the "self" is completely opposed to these reductionisms.

\section{Ecological thinking}

According to Capurro, "one answer to the destruction of human life brought by the information society is, as is also the case with the destruction of nature, the ecology of information and communication" (Capurro 1995: 40). He also states, "Technolo- 
gies of living mean to learn technologies concerning fulfilling our lives. Insofar as technologies of living are regarded as ecological ones, they are related to ideas transcending individuals" (Capurro 1995: 44). "Ecological thinking" means the pursuit of harmony as a whole. That is, being rampant with unconditional freedom of desires informed by a kind of postmodernist thought is regarded as an undesirable situation. Capurro presented his paper "Towards an Information Ecology" in 1990, where we can see that he had a basis in ecological thinking in the early years of his conception of information ethics. Ecological thinking also means to avoid "humanism" in the sense of Heideggerians, or human-centeredthinking. Capurro thinks that we should not subscribe to technological determinism but humane thinking, but this does not mean human-centered thinking in utilizing the environment with our partial and imperfect knowledge. Furthermore, in this kind of ecology concerning information environment, attentions are paid to pathological phenomena which appear in the intertwining between human lives and information technology. For example, Capurro mentions the problem of speeding, suggesting that we should consider not only the way the Internet is used to pursue efficiency or speed up our lives, driving us more and making us busier than now, but to get more spare time. He is also worried about the increasing number of children among heavy Internet users who lack concentration, are emotionally instable, or who are not good at human relationships. These topics can be regarded as the problems of human ecological systems from the viewpoint of ecological thinking.

We can see that Capurro tries to open up a third dimension which has neither a modern nor postmodern approach to information studies. Mentioning Aristotle, he tries to go back to the viewpoint where the confrontation between modernism and postmodernism or the separation between academic studies and technologies did not occur. Studies concerning information ethics or the information society tend to polarize into modernism (information democracy) and postmodernism (spiritual anarchism) which do not seem to provide us with adequate explanations. We can find few arguments that try to go beyond modernism and postmodernism to construct a new theoretical framework of information ethics. In that sense, Capurro's hermeneutic approach can be regarded as a pioneering work, giving us important suggestions to consider in the future development of information ethics.

\section{Capurro and Japanese Perspective}

Finally, I would like to briefly discuss the relationship between Capurro's hermeneutic approach and the Japanese perspective.

Capurro is interested in (ontological) distinctions between mono and koto, or between "reality ( $R e$ alität)" and "actuality (Wirklichkeit)" as proposed by Bin Kimura (1931- ), a noted Japanese psychoanalyst and a thinker. Mono and koto are concepts of Japanese language which mean "things" and "events", respectively. Kimura relates the word "reality" to the "essence" of something and "actuality" to what is "happening". He mentions that in Japanese they use mono and koto, where mono refers to things in there being while koto refers to what is happening. The world is the whole of what is happening, not of the things. Also the existences or activities of "I" and "you" are not mono but koto, that is, they are not "substances" in Japanese. Capurro thinks this is important for our thinking about the question of what he calls "information metaphysics" vs. "information ontology," the conflict between information-as-thing (Michael Buckland's term) and information-as-event (Capurro's concept to denote the "eventuality" in Heideggerian terms of the phenomenon), or between information as mono and as koto. Capurro says that Heidegger's criticism of the "Gestell" and what he calls the "Information Gestell" would look only to information as mono (things), but this is exactly what the book culture was. Libraries are full of mono. What the Internet brings is information as koto (events) and this is the main thought concerning "message", because a message is basically koto. It makes no sense to think of messages as "things" with some "characteristics." I agree with Capurro when he says that messages are basically koto. The concept of information is particularly problematic, and this is why he thinks that we must switch to the concept of "message" which is more dynamic.

It is natural that Kimura has a similar viewpoint of the hermeneutic approach because his work is based on Heidegger. On the other hand, Kimura also depends on the philosophy of Kitaro Nishida (1870-1945), who is called the first "philosopher" in Japan. Nishida himself practiced Zen and tried to systematize the eastern thought in terms of the western philosophy to overcome the separation between subjectivity and objectivity. Capurro himself has deepened his interest in Zen Buddhism and Japanese thought (e.g. Capurro 1999b, c) and promoted friendships with Japanese thinkers. 
The future relationship between Capurro's hermeneutic approach and Japanese thought will be interesting. The interaction between them is expected to bear fruitful outcomes in the development of information ethics.

\section{Acknowledgment}

I sincerely thank Professor Toru Nishigaki (University of Tokyo), Professor Takehiko Daikoku (Meiji University) and Professor Makoto Nakada (University of Tsukuba) for their useful advice in writing this paper. I also give my thanks to Ms. Leslie Tkach Kawasaki (Ph.D. Candidate, University of Tsukuba) for her help in polishing my English. Finally I thank Professor Rafael Capurro for giving me information, inspiration, and encouragement.

\section{References}

Capurro, Rafael (1986): Hermeneutik der Fachinformation, Freiburg, Alber, 239p.

Capurro, Rafael (1995): Leben im Informationszeitalter. Berlin, Akademie Verlag, 134p.

Capurro, Rafael (1999a): Ethos des Cyberspace, Wechse/wirkung, Dez.98/Jan., pp.6-9. http://www. capurro. de/cyberethos.htm

Capurro, Rafael (1999b): Die Wahrheit des Seins ist ein Schatten der Wahrheit des ZEN http://www. capurro. de/zen.htm

Capurro, Rafael (1999c): Gibt es eine europäische Philosophie? $\quad$ http://www.capurro.de/japphil.html

Capurro, Rafael (2000a): Was ist Angeletik? http://www. capurro.de/angeletik.htm

Capurro, Rafael (2000b): Hermeneutics and the phenomenon of information, Carl Mitcham, ed.: Metaphysics, Epistemology, and Technology. Research in Philosophy and Technology. Vol. 19, JAl / Elsevier Inc. pp. 79-85. http://www. capurro. de/ny86. htm

Capurro, Rafael (2001): Theorie der Botschaft. Beitrag zum Symposion: Transdisziplinäre Kommunikation. Aktuelle Be-Deutungen des Phänomens Kommunikation im fächerubegreifenden Dialog, Universität Salzburg, Österreich, 25.-26. April 2001 http://www. capurro. de/botschaft.htm

Capurro, Rafael (2003): Ethik im Netz. Stuttgart, Franz Steiner Verlag. Schriftenreihe zur MedienEthik, Bd. 2, 278p.

Debray, Régis (1991): Cours de médiologie générale, Éditions Gallimard.
Debray, Régis (1997): Transmittre, Éditions Odile Jacob.

Dreyfus, Hubert L. (1972): What computers can't do, The Limits of Artificial Intelligence, Revised Edition, Harper \& Row.

Dreyfus, Hubert L. (1991): Being-in-the-World, A Commentary on Heidegger's Being and Time, Division I, MIT Press.

Dreyfus, Hubert L. (2001): On the Internet, London, Routledge.

Foucault, Michel et al. (1988): Technologies of the self: a seminar with Michel Foucault, edited by Luther H. Martin, Huck Gutman, Patrick H. Hutton. University of Massachusetts Press

Kimura, Bin (1972): Hito to hito to no aida, Tokyo, Kobundo Publ.House. = (1995): Zwischen Mensch und Mensch. Strukturen japanischer Subjektivität. Darmstadt. Translated by Elmar Weinmayr.

Takenouchi, Tadashi (2002a): Information Retrieval and Hermeneutics: Hermeneutic Informatics According to Rafael Capurro, Journal of Library and Information Studies, Vol.1, Tsukuba, pp.113

Takenouchi, Tadashi (2002b): The Contribution of the Hermeneutic Approach to Socio-Information Studies, Journal of Socio-Information Studies, Vol.6, Ebetsu, pp.39-51 